Querido, S.J., Vergouw, D., Wigersma, L., Batenburg, R.S., Rond, M.E.J. de, Cate, O.T.J. ten. Dynamics of career choice among students in undergraduate medical courses. A BEME

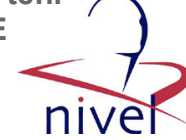

\begin{tabular}{|l|l|}
$\begin{array}{l}\text { Postprint } \\
\text { Version }\end{array}$ & 1.0 \\
\hline Journal website & http://dx.doi.org/10.3109/0142159X.2015.1074990 \\
\hline Pubmed link & $\underline{\text { http://www.ncbi.nlm.nih.gov/pubmed/26372112 }}$ \\
\hline DOI & $10.3109 / 0142159 X .2015 .1074990$ \\
\hline
\end{tabular}

This is a NIVEL certified Post Print, more info at http://www.nivel.eu

\title{
Dynamics of career choice among students in undergraduate medical courses. A BEME systematic review: BEME Guide No. 33
}

SoPHiE J. Querido, DAVID VERgouw, LOde Wigersma, RONALD S. BATENBURG, Marlies E. J. De Rond \& Olle T. J. TEN CATE

\begin{abstract}
Introduction: Due to the lack of a theoretically embedded overview of the recent literature on medical career decision-making, this study provides an outline of these dynamics. Since differences in educational routes to the medical degree likely affect career choice dynamics, this study focuses on medical career decision-making in educational systems with a Western European curriculum structure.

Methods: A systematic search of electronic databases (Medline, Embase) was conducted from January 2008 to November 2014. A panel of seven independent reviewers performed the data extraction, quality assessment and data synthesis using the Bland-Meurer model of medical specialty choice as a reference.

Results: Fifty-seven studies met the inclusion criteria for the review. Factors associated with specialty preference or career choice can be classified in five main categories: (1) medical school characteristics (e.g., curriculum structure), (2) student characteristics (e.g., age, personality), (3) student values (e.g., personal preference), (4) career needs to be satisfied (e.g., expected income, status, and work-life balance), and (5) perception of specialty characteristics (e.g., extracurricular or curricular experiences). Especially career needs and perceptions of specialty characteristics are often associated with medical career decision-making.

Conclusion: Our results support that medical career decisions are formed by a matching of perceptions of specialty characteristics with personal needs. However, the process of medical career decision-making is not yet fully understood. Besides identifying possible predictors, future research should focus on detecting interrelations between hypothesized predictors and identify the determinants and interrelations at the various stages of the medical career decision-making process.
\end{abstract}


Querido, S.J., Vergouw, D., Wigersma, L., Batenburg, R.S., Rond, M.E.J. de, Cate, O.T.J. ten. Dynamics of career choice among students in undergraduate medical courses. A BEME systematic review: BEME Guide No. 33. Medical Teacher: 2016, 38(1), 18-29

\section{INTRODUCTION}

For graduating doctors planning to specialize, choosing a residency is a major career decision and a defining phase in their professional life. Many enter medical school with a career plan or preference (Cleland et al. 2012), but few actually start a residency of that early preference (Kaur et al. 2014). One reason is that enrolling medical students appear to have misconceptions about the medical profession (Underwood et al. 1990; Nieuwhof et al. 2005; Soethout et al. 2008 b). As students progress through medical school, career plans and preferences tend to shift. These shifts are determined by the medical curriculum that usually does not expose students to the wide variety of specialties. Initial student preference for specialty training usually does not align with the health care workforce demands and with available residency vacancies (Avinashi \& Shouldice 2006; Pugno et al. 2007; Fukuda \& Harada 2010; Goldacre et al. 2010; Lefevre et al. 2010 b; Svirko et al.2013). As a result, specialties may either experience a shortage of residency applicants' primary choices, while the competition for other more popular specialties can be fierce. Students who cannot obtain the residency position of their first choice might switch to a less desirable training post; other may postpone their residency commencement and wait for the opportunity of their first choice. Ill-informed students may start a residency that leads to distress, possible reallocation or drop-out (Dodson \& Webb 2005; Vermeulen et al. 2011). The understanding of the medical career decision-making process is important to aid career counseling and thus prevent wrong choices, support medical graduates in their choice and promote faster choices. Career choice research has predominantly been performed in North America (US and Canada), Australia and the United Kingdom. Wijnen-Meijer et al. (2013) showed how different the educational routes to the medical degree are, as systems in various countries differ regarding medical school entry, curriculum length and structure, residency selection and postgraduate training structure. These differences likely affect career choice dynamics and consequently impede the comparison of results from studies performed in different educational systems. Therefore, we are particularly interested to explore the dynamics of medical career decision-making in educational systems with a curricular structure that is most common in Western European countries; students enter medical school directly after secondary school without a prior tertiary or college entry-level medical education program. Thus, a long integrated, one-tier undergraduate medical course. Furthermore, postgraduate specialty training follows directly after medical school or after a period of nonmandatory practice. This educational structure corresponds with the routes 1 and 2 (i.e., a medical school programme with students directly admitted from high school or primary school that is directly followed by postgraduate specialty training) from the classification by Wijnen-Meijer et al. (2013), as opposed to North-American structures.

Medical career preferences and determinants of medical career choice have been addressed abundantly in the literature, indicating that medical career decisionmaking is a dynamic, complex and multifactorial process (Burack et al. 1997; Reed et al. 2001). The Bland-Meurer model of medical specialty choice captures the most comprehensive outline of medical student career decision-making to date (Bland et al. 1995). This framework, which originates from a non-statistical meta analysis, suggests that medical specialty choice emerges from the matching of perceptions of specialty characteristics with personal and social needs. Perceptions and needs 
Querido, S.J., Vergouw, D., Wigersma, L., Batenburg, R.S., Rond, M.E.J. de, Cate, O.T.J. ten. Dynamics of career choice among students in undergraduate medical courses. A BEME systematic review: BEME Guide No. 33. Medical Teacher: 2016, 38(1), 18-29

which, in turn, are expected to be mediated by faculty and student characteristics as well as student values. Although the model was introduced two decades ago, suggested mediating influences and interrelations between hypothesized predictors are seldom explored. Most research only investigates the direct association of career choice with one or a few variables which hamper the interpretation of individual study results in relation to all hypothesized predictive variables.

Data of individual studies on career choice have often been synthesized (CamposOutcalt et al. 1995; Reed et al. 2001; Borges \& Savickas 2002; Senf et al. 2003; Straus et al. 2006; Shadbolt \& Bunker 2009). Most overviews limit their focus on (1) a single medical specialty (Senf et al. 2003; Shadbolt \& Bunker 2009), (2) a single theme or a limited number of potential predictors (Campos-Outcalt et al. 1995; Borges \& Savickas 2002; Borges et al. 2010), or (3) do not theoretically underpin the results (Straus et al. 2006). The only overview that we have identified not suffering from these three limitations is almost 15 years old (Reed et al. 2001).

Due to the lack of a theoretically embedded overview of the recent literature presenting the dynamics of medical career choice, our study aims to provide such an outline using the Bland-Meurer model as a reference. This literature synthesis was conducted to address the following research questions: What factors have been studied that may be associated to medical career decision-making in undergraduate medical students? How can the associated factors be embedded in a theoretical framework to explain career choice dynamics?

\section{METHODS}

A systematic literature review (SLR) was undertaken to explore the factors influencing preferences and choices for a medical career by synthesizing data from qualitative and quantitative methodologies.

\section{Search}

A search of Embase and Medline, 1 January 2008 to 1 November 2014, was undertaken to identify studies focusing on career preferences and choices of medical students. We developed a search strategy as shown in Table 1. Search terms had to be present in title or abstract. In addition, the reference lists of all included studies were hand searched for supplementary relevant studies.

\section{[TABLE 1]}

\section{Inclusion and exclusion}

Inclusion and exclusion criteria are presented in Table 2. The inclusion criteria were: (1) a study had to report results regarding factors associated with undergraduate medical students' career preferences or undergraduate medical students' professional choices, (2) a study had to have an observational design, i.e., retrospective or prospective cohort studies, or cross-sectional studies, (3) students had to be enrolled in a one-tier undergraduate medical course similar to most West-European undergraduate courses [see routes 1 and 2 mentioned in Wijnen-Meijer et al. (2013)].

\section{[TABLE 2]}

Studies were excluded when they did not report associations between factors and medical students' career preferences or professional choices. Studies among 
Querido, S.J., Vergouw, D., Wigersma, L., Batenburg, R.S., Rond, M.E.J. de, Cate, O.T.J. ten. Dynamics of career choice among students in undergraduate medical courses. A BEME systematic review: BEME Guide No. 33. Medical Teacher: 2016, 38(1), 18-29

residents, junior doctors or medical doctors were excluded as well as editorials, comments, and policy documents.

The first step of the selection was the initial screening of titles and abstracts for appropriateness by two researchers independently (S. Q. and D. V.). Results were compared and in the case of disagreement reassessed and discussed to reach consensus. Selected papers were then obtained in full-text, independently read by two researchers, and assessed for relevance (S. Q. and D. V.). In the case of disagreement, these results were also reassessed and discussed to reach consensus. When a mutually shared decision could not be reached, a third researcher (L. W.) reassessed the paper and results were again discussed to reach consensus.

\section{Data extraction and quality assessment}

A data extraction was performed by dividing the selected papers among a panel of seven assessors (S. Q., D. V., Ot. C., L. W., Md. R., P. H., and R.B.). Each paper was assessed by two researchers, independently synthesizing data regarding study design, study characteristics, methodological quality, and findings, using a data extraction form. Disagreements were first analyzed again and discussed by the two researches. If necessary, a third researcher was consulted and the article was assessed and discussed again by three researchers to reach consensus.

Levels of methodological quality were defined according to Soethout et al. (2004); and previously used by Ariens et al. (2001). The content is a seven category list of criteria: (a) study purpose, (b) study design, (c) response rate, (d) nature of the survey, (e) number of investigated factors (associated factors and career factors), (f) career or professional, and (g) statistical analysis. Four items (a, b, f, and g) could be awarded 0 or 2 points and three items (c, $d$, and e) could be awarded $0-3$ points, depending on the match between content and the criteria. Individual quality items were summed to calculate a total quality score with a minimum rate of 0 and a maximum of 17 points. The methodical quality was taken into account when analyzing the results. The results from studies with a low methodical quality are properly expected more uncertain and should be interpreted carefully.

\section{RESULTS}

\section{Selection of papers}

A flow chart of the selection of appropriate papers is provided in Figure 1.

\section{[FIGURE 1]}

The search strategy identified 1483 unique results in Medline and 76 in Embase, resulting in a total of 1559 papers. After screening titles and abstracts for relevance, 1274 articles were excluded. The main reasons for exclusion were an irrelevant study sample (e.g. midwifes or nurses) or non-empirical research paper (e.g. opinion or editorial). A consensus meeting was not needed. A total of 284 papers were obtained in full-text, one paper (Misselbrook \& Russell 2013) was not available through library, the publishing journal or through the author. After full-text evaluation, 225 papers were excluded because they did not fit the inclusion criteria, being (1) factors did not relate to preference or choice for a medical career, (2) the sample group concerned residents who were not retrospectively inquired about experiences during undergraduate training, or (3) the study was not performed in route 1 or 2 of the undergraduate course (Wijnen-Meijer et al. 2013). The additional check of the 
Querido, S.J., Vergouw, D., Wigersma, L., Batenburg, R.S., Rond, M.E.J. de, Cate, O.T.J. ten. Dynamics of career choice among students in undergraduate medical courses. A BEME systematic review: BEME Guide No. 33. Medical Teacher: 2016, 38(1), 18-29

reference lists of all identified papers yielded three supplementary papers that were not identified by searching the electronic databases. Therefore, final selection included 57 papers suitable for data synthesis.

\section{Origin and nature of the studies}

An overview of the characteristics of the identified studies including their methodological quality score is provided in Table 3.

\section{[TABLE 3]}

All of the 57 included and analyzed papers dealt with a sample group of medical students. Most of the studies were cross-sectional surveys $(n=47)$. Ten longitudinal studies; four of which used a pre- and post-design (Coffeng et al. 2009; Maudsley et al. 2010; Budd et al. 2011; Deutsch et al. 2013), five used a prospective cohort (Davis et al. 2010; Firth \& Wass 2011; Kiolbassa et al. 2011; Kumar \& Dhaliwal 2011; Clark et al. 2013), and one used a retrospective cohort (Tavakol et al. 2011) and there were three qualitative studies (Drinkwater et al. 2008; Thistlethwaite et al. 2008; Wigney \& Parker 2008).

Most of the identified studies regard the United Kingdom $(n=20,35 \%)$. Other studies were performed in Germany $(n=11,19 \%)$, Australia $(n=7,12 \%)$, the Netherlands $(n=5,9 \%)$, France $(n=4,7 \%)$, India $(n=3,5 \%)$, Saudi-Arabia $(n=2$, $4 \%)$, and Sweden, Denmark, Italy, Japan, or Spain $(n=1,2 \%)$. Almost all the studies clearly described the purpose of the study $(n=55,96 \%)$ and the study design $(n=48$, $84 \%)$. Two thirds $(n=36,63 \%)$ presented data collected at one university in a local survey with varying samples sizes (13-5400 subjects). A total of $47(82 \%)$ studies investigated a limited number of $(\geq 3)$ factors associated with the choice of medical specialty, six studies investigated two, and four studies investigated only factor for an association with medical specialty choice.

Six studies (10\%; two UK, two French, one German, and one Japanese) each with a total score of 16 or 17, can be regarded as high quality (Soethout et al. 2004). Quality scores of 13 through 15 were found in 31 (54\%) studies, 19 studies (33\%) showed a score in the range $8-12$, and two studies $(3 \%)$ had quality scores of $5-7$, predominantly showing the lack of information.

\section{Factors associated with career preference and career choice}

To provide an insightful overview of the factors significantly associated with specialty preference or career choice, Figure 2presents an overview of these factors classified in five categories according to the Bland-Meurer model (Bland et al. 1995). The original model consists of variables that determine medical students' specialty choice. We arranged the variables we found following the Bland-Meurer model: (1) medical school characteristics, (2) student characteristics, (3) student values (incoming-graduate), (4) needs to satisfy, and (5) perception of specialty characteristics. In the Bland-Meurer model, specialty choice is suggested to be essentially established by matching perceptions of specialty characteristics to personal and social needs. Needs that originate from the values that a student holds, which in turn are affected by many student characteristics, faculty characteristics, and personal developments during education. For the inclusion of factors in Figure 2, such interrelations did not necessarily have to be examined. Factors that are assumed to be directly associated with the process of career decision-making are presented by Figure 2 as well. 
Querido, S.J., Vergouw, D., Wigersma, L., Batenburg, R.S., Rond, M.E.J. de, Cate, O.T.J. ten. Dynamics of career choice among students in undergraduate medical courses. A BEME systematic review: BEME Guide No. 33. Medical Teacher: 2016, 38(1), 18-29

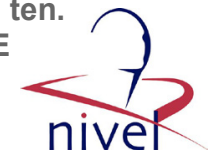

\section{[FIGURE 2]}

\section{Medical school characteristics}

Medical school characteristics are suggested to affect career choice by influencing the students' personal values and their perceptions of specialty characteristics. When applying to medical school, students may take their impressions of a school such as its ownership (private or public), mission, and orientation/structure into account. Furthermore, the selection of students may differ between medical schools due to policies that favor student characteristics or due to indirect influences of the selection committee. During medical school, students' perceptions and preferences may be influenced by the faculty values and institutional culture. The curriculum format and content, as determined by the curriculum committee, might as well influence students' career preferences and choices.

Two unique studies revealed that career choices differed between students from different medical schools (Cleland et al. 2012; Svirko et al. 2013). While Svirko et al. (2013) showed a regional difference, Cleland et al. (2012) showed that differences relate to both student variables and variation in medical school education and culture. Two other studies provided insight on the influence of habitus (variation in medical school education and culture) by showing that the sequencing of clinical rotations (Coffeng et al. 2009) or curricular design (traditional versus problem based) (Kuhnigk et al. 2009) affect (the development of) career preferences.

\section{Student characteristics}

Several studies suggest that student characteristics affect career choice through the values that people hold, which influences their needs in fulfilling a career. Half $(n=28,49 \%)$ of the included studies find an association between specialty choice and student characteristics. Inherent student characteristics (i.e., gender, personality, and age) as well as environmental student characteristics (i.e., geographic, study year, ethnicity, and education of parents) have been associated with career choice. However, the factors age and background were only associated with career choice in two studies which we identified to be of a low methodological quality (Ibrahim et al. 2014) (12 points) and (Clark et al. 2013) (10 points).

One-third of the studies reported gender as a direct determinant or a factor associated with medical career choice. Females appear more attracted to work with chronic patients, palliative care and a controllable lifestyle. Male students were more inclined to technology-oriented work, acute patients and prestige. In contrast, three studies found no gender differences in career preferences (Maiorova et al. 2008; Heiligers 2012; Diderichsen et al. 2013). Swedish male and female final year medical students opted for similar specialties and did not differ in motivational factors (Diderichsen et al. 2013). A Dutch study (Maiorova et al. 2008) found a bivariate association between gender and the preference for general practice. However, after correction for other variables (i.e., background characteristics, patients, and type of work preference, and self-assessed likelihood of becoming a general practitioner) this relationship did not hold. Comparable results were obtained by another Dutch study in which the gender association disappeared when correcting for living with a partner (Heiligers 2012).

\section{Student values}


Querido, S.J., Vergouw, D., Wigersma, L., Batenburg, R.S., Rond, M.E.J. de, Cate, O.T.J. ten. Dynamics of career choice among students in undergraduate medical courses. A BEME systematic review: BEME Guide No. 33. Medical Teacher: 2016, 38(1), 18-29

Most medical students start medical school with initial values which may evolve due to maturation, life events, and financial debt during medical training (Bland et al. 1995).

Three studies found associations between factors that may affect student values (i.e., marital status and academic performance) and medical career preference in incoming students and for final year students. A study by Abdulghani et al. (2013) showed that marital status is associated with career choice. Heiligers (2012) suggest that students who are married, or live with a partner, may have other priorities, due to family related issues and spouse expectations. Academic achievement is, according to Soethout et al. (2008a), weakly associated with medical student career preferences.

Eight studies present direct associations between actual student values and career choice. A positive attitude towards the patient group of the specialty and a personal preference for a medical career are associated with the medical career choice of graduating students. However, five of the studies in which such an association was identified, were regarded as being of a low methodological quality ( $<13$ points).

\section{Satisfying (personal) career needs}

Medical students have (personal) career needs that they wish to fulfill in their future career and their professional lives. Half of the included studies show an association between career choice and career needs. These can be classified as personal needs, societal needs, and expectations of others. Personal needs are most frequently associated with career choice. Associated personal needs are expected salary $(n=17)$, career options $(n=14)$, status $(n=32)$, work-life balance $(n=12)$, the labor content (e.g., type of patients or medical procedures; $n=12)$, lifestyle $(n=12)$, e.g. habits, attitudes, economic level, etc., that together constitute the mode of living of an individual or group). Most studies however do not clearly define the factor lifestyle; it usually refers to concerns about raising a family, alongside professional demands (Coulston et al. 2012). Other frequently associated personal needs with career choice are working hours $(n=12)$, intellectual satisfaction $(n=7$; e.g., the fulfillment of intellectual needs), location/type of work $(n=5)$, and challenging work $(n=3)$. The factors physical and emotional workload, professional autonomy and scope of selfpractice are respectively found in two studies of low methodological quality $(\leq 10$ points) and two studies with a moderate methodological quality ( $\leq 14$ points). Societal needs (i.e., the wish to serve society) and expectations of others have much less often been associated with career choice than personal needs. Three studies particularly report an association of the societal need of altruism to career choice. Altruism being meant as "the wish to make a difference to peoples" or "wanting to help people" (Maudsley et al. 2010). Other factors associated with career decisionmaking that relate to the expectations of others are: the opinion of others, career counseling and parental preferences.

\section{Perception of specialty characteristics}

According to the Bland-Meurer model specialty choice is essentially established by a matching of personal career needs with student perceptions of specialty characteristics. Actual student perceptions are rarely inquired by the selected studies. Only two studies associated an actual student perception (i.e., the perception of the 
Querido, S.J., Vergouw, D., Wigersma, L., Batenburg, R.S., Rond, M.E.J. de, Cate, O.T.J. ten. Dynamics of career choice among students in undergraduate medical courses. A BEME systematic review: BEME Guide No. 33. Medical Teacher: 2016, 38(1), 18-29

likelihood to obtain a residency position) with career choice. According to Baller et al. (2013), significant differences were seen among female students who mentioned that the competition regarding a residency position was of influence. These studies, however, were identified as being of a low methodological quality ( $\leq 10$ points). More than half $(n=35,61 \%)$ of all identified studies found a direct association between experiences during medical school that are expected to influence students' perception of a specialty and career choice. Curricular experiences such as (clinical) courses, rotations, electives, lectures, performing medical procedures, and contact with a patient group were most often associated with career choice. These experiences contribute to the level of interest and therefore of influence on their medical career choice.

However, extracurricular experiences (e.g. voluntary or paid work) (Robbins et al. 2011) are also mentioned as an important experience, as well as experiences in a student's personal life. For example, a psychiatric family member or acquaintances, positively influences a career choice for psychiatry (Lempp et al. 2012; Baller et al. 2013). Or illness yourself as a child (Bindal et al. 2011), and the influence of a role model or mentor may affect your preference, this could be in a positive or negative way. Evidence for the influence of these experiences is limited since they are associated with career choice in a single or two studies; specialty representation in the media or internet, perception of career options, experiences prior to medical school, perception of gender differences, and perception of status. Especially for the last three of these, the studies in which these associations were identified are of a low methodical quality ( $\leq 12$ points).

\section{DISCUSSION}

In this research, we provide a theoretically embedded overview of the recent literature on the dynamics of medical career decision-making in educational systems with a Western European curriculum structure. Based on the 57 studies selected from a SLR, our results, as summarized in Table 4, show that factors often associated with medical career decision-making in studies with methodological quality are: perceptions of specialty characteristics gained from curricular, extracurricular and personal experiences in health care, personal career needs (e.g., expected income, career options, status, work-life balance, labor content, lifestyle, working hours) and gender. Although recent literature prevalently focuses on student characteristics, we found indications that medical school characteristics such as curriculum design are also associated with career decision-making. Research into these influences is however still scarce.

\section{[TABLE 4]}

Based on our data synthesis, we support that students rationally match perceptions of different specialties' characteristics against a checklist of personal needs to form their specialty preference or medical career choice (Bland et al. 1995). The interrelations between hypothesized predictors and the needs and perceptions tradeoff are however barely described as the literature mainly investigates direct associations between predictors and medical career decision-making. Within the literature, only the interrelation between gender and medical career choice has received much attention. Male and female career decision-making is known to differ (Soethout et al. 2008a; Lefevre et al. 2010a,b; Kiolbassa et al. 2011; Malhi 2011; van 
Querido, S.J., Vergouw, D., Wigersma, L., Batenburg, R.S., Rond, M.E.J. de, Cate, O.T.J. ten. Dynamics of career choice among students in undergraduate medical courses. A BEME systematic review: BEME Guide No. 33. Medical Teacher: 2016, 38(1), 18-29

Tongeren-Alers et al. 2011; Cleland et al. 2012; Gedrose et al. 2012; Gibis et al. 2012; Heiligers 2012; Mehmood et al. 2013; Cleland et al. 2014; Ibrahim et al. 2014). Male students appear more externally motivated by salary, status, and the opportunity to implement technical activities and probably therefore more often opt for technical and instrumental oriented specialties (e.g., surgery) (Heiligers 2012). Female students, on the other hand, are more intrinsically motivated by patient related activities, humanistic and altruistic reasons, and opt for relationship-oriented specialties (e.g., family medicine and pediatrics) (Malhi et al. 2011; van TongerenAlers et al. 2011; Cleland et al. 2012; Gedrose et al. 2012; Heiligers 2012). Furthermore, compared to men, women expect their careers to be negatively influenced by their future family lives (van Tongeren-Alers et al. 2011). Due to the higher compatibility with family life, women tend to prefer primary care careers over a medical specialty (Heiligers 2012; Heinz \& Jacob 2012; Mehmood et al. 2013). However, some studies suggest that this is no longer only a female issue because family arguments seem to become more important among men as well (Gibis et al. 2012; Heiligers 2012; Diderichsen et al. 2013).

Whether such interrelations also exist for factors as personality, ethnicity or incoming career preference is unclear. Studies reporting survey data have so far not identified many conflicts between student values and career decision-making. This may indicate that, after decades of research, we still do not fully understand the process of career decision-making. In this light, qualitative research may provide more insight into the differences between groups of students and the possible causes and interrelations among hypothesized predictors.

Most studies involve surveys. To obtain more elaborate insight in choice mechanisms, qualitative studies, such as interviews, are needed. Interviews can prompt subjects to explain motives more deeply and help understand relationships between various factors. Even more insightful may be longitudinal interview studies to monitor students' changes in career argumentation.

To structure the data synthesis, we used the outline of the Bland-Meurer model of medical specialty choice as a reference. However, in the identified studies, career preference and career choice are ambiguously used as dependent variables, as these terms appoint to different stages in the career decision-making process (Vroom 1964; Matteson \& Smith 1977; Nieman et al. 1989). During medical school, career decision-making is assumed to evolve. Students first are likely to have one or more non-committal career preferences which are expected to be purely influenced by the perception of the content of work. As students' progress through medical school and gain experience, they are likely to become more pragmatic. Possible barriers to residency selection (e.g., work-life balance, job opportunities) are assumed to play an important role in coming to a more binding career choice (Vroom 1964; Matteson $\&$ Smith 1977). Since many of the studies included in our review inquired the interest of medical students, it was often unclear whether preferences or choices were reported. This makes it difficult to distinguish predictors for medical career preference and medical career choice. We hypothesize that while students progress through their studies, career preferences, guided by intrinsic factors of genuine content interest become gradually supplemented or replaced by extrinsic factors that limit their scope of choice options. An indication for this hypothesis is found when a subgroup analysis compared four studies performed among first-year students (Hughes et al. 2008; Pedersen et al. 2011; van Tongeren-Aleres et al. 2011; Cleland 
Querido, S.J., Vergouw, D., Wigersma, L., Batenburg, R.S., Rond, M.E.J. de, Cate, O.T.J. ten. Dynamics of career choice among students in undergraduate medical courses. A BEME systematic review: BEME Guide No. 33. Medical Teacher: 2016, 38(1), 18-29

et al. 2012) with 13 studies performed among final-year medical students (Maiorova et al. 2008; Lefevre et al. 2010a,b; Bindal et al. 2011; Firth \& Wass 2011; Ravindra \& Fitzgerald 2011; Andlauer et al.2012; Gedrose et al. 2012; Diderichsen et al. 2013; Ferrari et al. 2013; Halder et al. 2013; Andlauer et al. 2013; Svirko et al.2013). Factors solely associated with specialty preferences in first-year medical students appear more personal oriented (e.g., geography, self-confidence, and positive attitude toward patient population) compared to factors solely associated in final-year students which appear to be more specialty oriented (e.g., lifestyle, status, workload, specialty representation by media, and personal experiences in specific specialty). To provide more insight into career decision-making and the interrelation among predictors in the different stages of this process, longitudinal studies that follow career preferences during undergraduate medical training are necessary. Most of the performed research is based on cross-sectional design inventorying career decisionmaking on a single time point or retrospective with the risk of distortion of memory about earlier preferences.

\section{Strengths and limitations}

Other than just enumerating predictive factors, our study provides a theoretically embedded overview of the recent literature on the dynamics of career choice using the Bland-Meurer model. By doing so, we provided information on which hypothesized predictors are identified in recent research and how these factors are possibly related to each other and explain career choice dynamics. This shows what is currently known and what the gaps in the current knowledge of medical career decision-making are. Thus, providing direction for future research.

Since the differences in educational routes around the world likely affect career choice dynamics, we chose to only synthesize data from studies in educational settings comparable to the one-tier undergraduate medical course as commonly adopted in Western European countries. This provides a more comprehensible interpretation for researchers and career counselors from countries adopting such an undergraduate educational system. However, even countries which we included may differ in terms of social and cultural background. These differences should still be accounted for when interpreting the results to a specific setting. The recently introduced two-cycle bachelor and master model in some European countries do not seem to have affected student career considerations (Van den Broek et al. 2010, 2013).

Although we included the most prevalently used educational system worldwide (Wijnen-Meijer et al. 2013), our choice led to the exclusion of studies performed in North America. Due to this choice, we might have missed some hypothesized predictors as a substantial part of the medical career decision-making research originates from the US and Canada. A comparison between our results and those of a review that did not restrict the inclusion of North American studies (Senf et al. 2003) indeed showed some discrepancies. Faculty composition, medical school admission, students' socioeconomic and academic background, and indebtedness are factors that, as opposed to our data synthesis, were associated with medical career decisionmaking in North American studies. Whether these factors are general predictors is unclear. It might very well be that the known social, cultural and educational differences between North America and other countries explain why these factors were not denoted as predictors in our data synthesis. 
Querido, S.J., Vergouw, D., Wigersma, L., Batenburg, R.S., Rond, M.E.J. de, Cate, O.T.J. ten. Dynamics of career choice among students in undergraduate medical courses. A BEME systematic review: BEME Guide No. 33. Medical Teacher: 2016, 38(1), 18-29

What might have led to omission of some hypothesized predictors is that our data synthesis only included recent studies (2008-2014). In general, acknowledged predictors could have been ignored by recent studies in search of new associations. However, when we compare our findings with those from earlier published reviews (Bland et al. 1995; Reed et al. 2001; Shadbolt \& Bunker 2009), we found two additional predictors (i.e., the probability of obtaining a residency position, and the perception of emotional workload). In these additional predictors, the current shortage on the labor market might be reflected.

The exclusion of articles published in languages other than Dutch, English, or German led to the omission of 66 (4.2\%) of the 1559 initially through database searching identified papers. Since original articles written in languages such as French, Spanish, Hebrew, Hungarian, Swedish, Danish, and Portuguese were omitted from the initial selection of papers, potential predictors might have been absent in the presented overview. The same holds for employing the search strategy to only two literature databases (Medline and Embase). Although an additional reference screening was undertaken, recent grey literature may still have been missed. For all studies included in the data synthesis, the levels of methodological quality was, regardless of study design, assessed by a criteria list provided by Soethout et al. (2004). These criteria however slightly favor quantitative studies over qualitative studies. Due to their non-statistical nature, qualitative studies can only obtain a maximum score of 15 where quantitative studies can obtain a maximum of 17 points. Consequently, the current methodological quality of the study by Wigney \& Parker (2008) is regarded as low (11 points), while correcting for study design would make it a study with moderate methodological quality (13 points).

In our overview, we presented factors with a known association with medical career decision-making in general. We did not discriminate between factors associated to specialty-specific career preferences. Some factors in our overview are presented as generally applicable while in the individual studies they were specifically associated to a particular specialty choice or preference. The generalizability was our inference.

\section{CONCLUSION AND RECOMMENDATIONS}

There is a significant amount of medical career decision-making literature that provides the following factors as predictors of medical career decision-making: perceptions of specialty characteristics gained from curricular, extracurricular and personal experiences in health care, personal career needs (e.g., expected income, career options, status, work-life balance, labor content, lifestyle, and working hours), and gender. However, the data synthesis using the Bland-Meurer model as a reference shows that the process of medical career decision-making is not yet fully understood. Besides identifying possible predictors, future research should also focus on detecting interrelations between hypothesized predictors and identify the determinants and interrelations at the various stages of the medical career decisionmaking process. Since medical career decision-making is a dynamic, complex, and multifactorial process, qualitative research is expected to provide useful insights into this process. Next to recommendations for further research, the data synthesis appears to support practical recommendations. Medical school leadership and curriculum committees should be aware of the impact of school characteristics such as curriculum organization and design on career decision-making processes. Furthermore, career counseling should stimulate students to gain (clinical) 
Querido, S.J., Vergouw, D., Wigersma, L., Batenburg, R.S., Rond, M.E.J. de, Cate, O.T.J. ten. Dynamics of career choice among students in undergraduate medical courses. A BEME systematic review: BEME Guide No. 33. Medical Teacher: 2016, 38(1), 18-29

experiences in different specialties, to discover their personal career needs, and the matching of career needs to specialty perceptions.

Appendix 1, table of study characteristics and methodological quality of included studies, is available as Supplementary Material.

\section{Acknowledgements}

The authors acknowledge the support of liberian specialist P.H. Wiersma of the Utrecht University for support during the search strategy and Phil Heiligers, $\mathrm{PhD}$, senior researcher at Nivel, for her part in the assessors' panel.

\section{Declaration of interest:}

The authors report no declarations of interest.

\section{REFERENCES}

Abdulghani HM, Al-Shaikh G, Alhujayri AK, Alohaideb NS, Alsaeed HA, Alshoyayeb IS, Alyahya MM, Alhaqwi Al, Shaik SA. 2013. What determines the selection of undergraduate medical students to the specialty of their future careers? Med Teach 35:S25-S30.

Al-Nuaimi Y, McGrouther G, Bayat A. 2008. Modernisering medical careers and factors influencing career choices of medical students. Br J Hosp Med 69(3):163-166.

Andlauer O, Guicherd W, Haffen E, Sechter D, Bonin B, Seed K, Lydall G, Malik A, Bhugra D, Howard R. 2012. Factors influencing French medical students towards a career in psychiatry. Psychiatr Danub 24(Suppl 1):S185-S190.

Andlauer O, Van Effenterre A, Haffen E, Sechter D, Farooq K, Lydall G, Malik A, Bhugra D. 2013. Encouraging French medical students to choose a career in psychiatry: How and why? Int Rev Psychiatry 25(4):460-465.

Ariens GAM, Van Mechelen W, Bongers PM, Bouter LM, Van der Wal G. 2001. Psychosocial risk factors for neck pain: A systematic review. Am J Ind Med 39:180-193.

Avinashi V, Shouldice E. 2006. Increasing interest in family medicine. CMAJ 174:761-762.

Baller FAE, Ludwig KV, Kinas-Gnadt Olivares CL, Graef-Calliess IT. 2013. Exploring the ideas and expectations of German medical students towards career choices and the specialty of psychiatry. Int Rev Psychiatry 25(4):425-430.

Bindal T, Wall D, Goodyear HM. 2011. Medical students' view on selecting paediatrics as a career choice. Eur J Pediatr 170:1193-1199.

Bland CJ, Meurer LN, Maldona G. 1995. Determinants of primary care specialty choice: A non-statistical meta-analysis of the literature. Acad Med 70(7):620-641.

Borges NJ, Savickas ML. 2002. Personality and medical specialty choice: A literature review and integration. J Career Assess 10(3):362-380.

Borges NJ, Navarro AM, Grover A, Hodan JD. 2010. How, when and why do physicians choose careers in academic medicine? A literature review. Acad Med 85(4):680-686.

Budd S, Kelley R, Day R, Variend H, Dogra N. 2011. Students attitudes to psychiatry and their clinical placements. Med Teach 33:e586-e592.

Burack JH, Irby DM, Carline JD, Ambrozy DM, Ellsbury KE, Stritter FT. 1997. A study of medical students' specialty-choice-pathways: Trying on possible selves. Acad Med 72:534-541.

Campos-Outcalt D, Senf J, Watkins AJ, Bastacky S. 1995. The effects of medical school curricula, faculty role models, and biomedical research support on choice of generalist physician careers: A review and quality assessment of the literature. Acad Med 70(7):611619.

Clark TR, Freedman SB, Croft AJ, Dalton HE, Luscombe GM, Brown DJ, Frommer MS. 2013. Medical graduates becoming rural doctors: Rural background versus extended rural placement. Med J Aust 199(11):779-782.

Cleland J, Johnston PW, French FH, Needham G. 2012. Associations between medical school and career preferences in Year 1 medical students in Scotland. Med Educ 46:473484. 
Querido, S.J., Vergouw, D., Wigersma, L., Batenburg, R.S., Rond, M.E.J. de, Cate, O.T.J. ten. Dynamics of career choice among students in undergraduate medical courses. A BEME systematic review: BEME Guide No. 33. Medical Teacher: 2016, 38(1), 18-29

Cleland JA, Johnston PW, Anthony M, Khan N, Scott NW. 2014. A survey of factors influencing career preference in new-entrant and exiting medical students from four UK medical schools. Med Educ 14:151.

Coffeng LE, Visscher AJE, ten Cate OTHJ. 2009. The influence of early clinical experiences on career preference of male and female medical students. Med Teach 31:e323-e326.

Coulston C, Vollmer-Conna U, Malhi G. 2012. Female medical students: Who might make the cut? Psychiatry Res 200:457-463.

Davis CR, O'Donoghue JM, McPhail J, Green AR. 2010. How to improve plastic surgery knowledge, skills and career interest in undergraduates in one day. J Plastic Reconstr Aesthet Surg 63:1677-1681.

Deutsch T, Honingschmid P, Frese T, Sandholzer H. 2013. Early community-based family practice elective positively influences medical students' career considerations - a pre-postcomparison. Fam Pract 14: 24.

Deutsch T, Lippmann S, Frese T, Sandholzer H. 2014. Gewinnung hausartzlichen nachwuchses - zusammenhang zwischen praxisorientierter lehre und karriereentscheidung. Gesundheidswesen 76:26-31.

Diderichsen S, Johansson EE, Verdonk P, Lagro-Janssen T, Hamberg K.

2013. Few gender differences in specialty preferences and motivational factors: A crosssectional Swedish study on last-year medical students.

Med Educ 13:39.

Dodson TF, Webb AL. 2005. Why do residents leave general surgery? The hidden problem in today's programs. Curr Surg 62(1):128-131.

Drinkwater J, Tully MP, Dornan T. 2008. The effect of gender on medical students' aspirations: A qualitative study. Med Educ 42(4):420-426.

Ferrari S, Reggianini C, Mattei G, Rigatelli M, Pingani L, Bhugra D. 2013.

International study of student career choice in psychiatry (ISoSCCiP): Results from Modena, Italy. Int Rev Psychiatry 25(4):450-459.

Firth A, Wass V. 2011. The impact of general practice attachments on Foundation Doctors:

Achieving the goals of Modernising Medical Careers. Educ Prim Care 22:314-320.

Fukuda Y, Harada T. 2010. Gender differences in specialty preference and mismatch with real needs in Japanese medical students. BMC Med Educ 10:15.

Gedrose B, Wonneberger C, Ju"nger J, Robra BP, Schmidt A, Stosch C, Wagner R, Scherer M, Po"ge K, Rothe K, van den Bussche H. 2012.

Haben Frauen am Ende des Medizinstudiums andere Vorstellungen uu"ber Berufsta"tigkeit und Arbeitszeit als ihre ma"nnlichen Kollegen? Ergebnisse einer multizentrischen postalischen Befragung. Dtsch Med Wochenschr 137(23):1242-1247.

Gibis B, Heinz A, Jacob R, Muu“ller CH. 2012. The career expectations of medical students: Findings of a nationwide survey in Germany. Dtsch Arztebl Int 109(18):327-332.

Goldacre MJ, Laxton L, Lambert TW. 2010. Medical graduates' early career choices of specialty and their eventual specialty destinations: UK prospective cohort studies. BMJ 6:341.

Heiligers PJM. 2012. Gender differences in medical students' motives and career choice. Med Educ 12:82.

Halder N, Hadjidemetriou C, Pearson R, Farooq K, Lydall GJ, Malik A, Bhugra D. 2013. Student career choice in psychiatry: Findings from $18 \mathrm{UK}$ medical schools. Int Rev Psychiatry 25(4):438-444.

Heinz A, Jacob R. 2012. Medizinstudenten und ihre Berufsperspektiven. In welcher Fachartzrichtung, wo und wie wollen sie arbeiten? Bundesgesundheitsbl 55:245-253.

Hermann K, Buchholz A, Loh A, Kiolbassa K, Miksch A, Joos S, Go"tz K.

2012. Entwicklung, faktorenanalytische .berpruu"fung und psychometrische Evaluierung eines Fragebogens zur Gebietswahl von Medizinstudierenden. Gesundheitswesen 74(7):426-434.

Hughes NJ, Soiza RL, Chua M, Hoyle GE, MacDonald A, Primrose WR, Seymour DG. 2008. Medical students attitudes toward older people and willingness to consider a career in geriatric medicine. J Am Geriatr Soc 56(2):334-338.

Ibrahim M, Fanshawe A, Patel V, Goswami K, Chilvers G, Ting M, Pila Vakis Y, Rao C, Athanasiou T. 2014. What factors influence Britsh medical students' career intentions? Med Teach 36:1064-1072. 
Querido, S.J., Vergouw, D., Wigersma, L., Batenburg, R.S., Rond, M.E.J. de, Cate, O.T.J. ten. Dynamics of career choice among students in undergraduate medical courses. A BEME systematic review: BEME Guide No. 33. Medical Teacher: 2016, 38(1), 18-29

Kaur B, Carberry A, Hogan N, Roberton D, Beilby J. 2014. The medical schools outcomes database project: Australian medical student characteristics. BMC Med Educ 29(14):180.

Kiolbassa K, Miksch A, Hermann K, Loh A, Szecsenyi J, Joos S, Goetz K. 2011. Becoming a general practitioner - Which factors have most impact on career choice of medical students? Fam Pract 12:25.

Kuhnigk O, Hofmann M, Bo"thern AM, Haufs C, Bullinger M, Harendza S.

2009. Influence of educational programs on attitudes of medical students towards psychiatry: Effects of psychiatric experience, gender, and personality dimensions. Med Educ 31:e303e310.

Kumar R, Dhaliwal U. 2011. Career choices of undergraduate medical students. Natl Med J India 24(3):166-169.

Lampe L, Coulston C, Walter G, Malhi G. 2010. Familiarity breeds respect: Attitudes of medical students towards psychiatry following a clinical attachment. Aust Psychiatry 18(4):348-353.

Lefevre JH, Karila L, Kerneis S, Roupret M. 2010a. Motivation of French medical students to pursue surgical careers: Results of national survey of 1742 students. J Visceral Surgery 147:e181-e186.

Lefevre JH, Roupret M, Kerneis S, Karila L. 2010b. Career choices of medical students: A national survey of 1780 students. Med Educ 44(6):603-612.

Lempp T, Neuhoff N, Renner T, Vloet TD, Fischer H, Stegemann T, Zepf FD, Ro"bner V, Ko"lch M, Haessler F, et al. 2012. Who wants to become a child psychiatrist? Lessons for future recruitment strategies from a student survey at seven German medical schools. Acad Psychiatry 36:246-251.

Maiorova T, Stevens F, van der Zee J, Boode B, Scherpbier A. 2008.

Shortage in general practice despite the feminisation of the medical workforce: A seeming paradox? A cohort study. Health Serv Res 17(8):262.

Malhi GS, Coulston CM, Parker GB, Cashman E, Walter G, Lampe LA, Vollmer-Conna U. 2011. Who picks psychiatry? Perceptions, preferences and personality of medical students. Aus NZ J Psychiatry 45(10):861-870.

Matteson MT, Smith SV. 1977. Selection of medical specialties: Preferences versus choices. Med Educ 52(7):548-554.

Maudsley G, Williams L, Taylor D. 2010. Medical students' and prospective medical students' uncertainties about career intentions: Cross-sectional and longitudinal studies. Med Teach 32:e143-e151.

Mehmood SI, Khan MA, Walsh KM, Borleffs JCC. 2013. Personality types and specialist choices in medical students. Med Teach 35:63-68.

Misselbrook G, Russell E. 2013. Who wants to be an acute medic? A survey of junior doctors attitudes towards and beliefs surrounding a career in acute medicine. Acute Med 12(4):201-207.

Mulla S, Watmough S, Waddelove C. 2012. Medical students' views and understanding of a career in academic medicine. Br J Hosp Med 73(7):401-405.

Nieman LZ, Holbert D, Bremer CC, Nieman LJ. 1989. Specialty career decision making of third-year medical students. Fam Med 21(5):359-363.

Nieuwhof MGH, Rademakers JJDJM, Kuyvenhoven MM, Soethout MBM, Ten Cate Th J. 2005. Students' conceptions of the medical profession: An interview study. Med Teach 27(8):709-714.

Pedersen LT, Hasle Bak N, Dissing AS, Peterson BH. 2011. Gender bias in specialty preferences among Danish medical students: A cross-sectional study. Dan Med Bul 58(9):A304.

Praharaj SK, Behere RV, Deora S, Sharma PS. 2013. Psychiatric specialization as an option for medical students in the Indian context. Int Rev Psychiatry 25(4):419-424.

Pugno PA, McGaha A, Schmittling GT, DeVilbiss A, Kahn Jr NB. 2007.

Results of the 2007 National Resident Matching Program. Fam Med 38: 555-564.

Rabadan FE, Hildago JL. 2010. Changes in the knowledge of and attitudes toward family medicine after completing a primary care course. Fam Med 42(1):35-40.

Ravindra P, Fitzgerald JEF. 2011. Defining surgical role models and their influence on career choice. World J Surg 35:704-709. 
Querido, S.J., Vergouw, D., Wigersma, L., Batenburg, R.S., Rond, M.E.J. de, Cate, O.T.J. ten. Dynamics of career choice among students in undergraduate medical courses. A BEME systematic review: BEME Guide No. 33. Medical Teacher: 2016, 38(1), 18-29

Reed VA, Jernstedt GC, Reber ES. 2001. Understanding and improving medical student specialty choice: A synthesis of the literature using decision theory as a referent. Teach Learn Med 13(2):117-129.

Robbins TD, Crocker-Buque T, Forrester-Paton C, Cantlay A, Gladman JRF, Gordon AL. 2011. Geriatrics is rewarding but lacks earning potential and prestige: Responses from the national medical student survey of attitudes to and perceptions of geriatric medicine. Age Ageing 40(3):405-408.

Robertson T, Walter G, Soh N, Hunt G, Cleary M, Malhi G. 2009. Medical students' attitudes towards a career in psychiatry before and after viewing a promotional DVD. Aust Psychiatry 17(4):311-317.

Senf JH, Campos-Outcalt D, Kutob R. 2003. Factors related to the choice of family medicine: A reassessment and literature review. J Am Board Fam Med 16(6):502-512.

Shadbolt N, Bunker J. 2009. Choosing general practice - A review of career choice determinants. Aust Fam Physician 38(1-2):53-55.

Soethout MBM, Ten Cate OTJ, Van der Wal G. 2004. Factors associated with the nature, timing and stability of the specialty career choices of recently graduated doctors in European countries. Med Educ 9:24.

Soethout MBM, Heymans MW, ten Cate OThJ. 2008a. Career preference and medical students' biographical characteristics and academic achievement. Med Teach 30:e15-e22.

Soethout MBM, Ten Cate OTJ, van der Wal G. 2008b. Correlations of knowledge and preference of medical students for a specialty career: A case-study of youth health care. BMC Public Health 8:14.

Steinhauser J, Miksch A, Hermann K, Joos S, Loh A, Gotz K. 2013. Wie sehen Medizinstudierende die Allgemeinmedizin? Ergebnisse einer onlinebasierten Querschnittstudie in Baden-Wurttemberg. Dtsch Med Wochenschr 138(42):2137-2142.

Straus SE, Straus C, Tzanetos K. 2006. Career choice in academic medicine: Systematic review. J Gen Intern Med 21(12):1222-1229.

Subba SH, Binu VS, Kotian MS, Joseph N, Mahamood AB, Dixit N, George A, Kumar P, Acharya S, Reddy P. 2012. Future specialization interests among medical students in southern India. Natl Med J India 25(4):226-229.

Svirko E, Goldacre MJ, Lambert T. 2013. Career choices of the United Kingdom medical graduates of 2005, 2008 and 2009: Questionnaire surveys. Med Teach 35(5):365-375.

Takeda Y, Morio K, Snell L, Otaki J, Takahashi M, Kai I. 2013. Characteristic profiles among students and junior doctors with specific career preferences. Med Educ 13:125.

Tambyraja AL, McCrea CA, Parks RW, Garden OJ. 2008. Attitudes of medical students towards careers in general surgery. World J Surg 32: 960-963.

Tavakol S, Dennick R, Tavakol M. 2011. Empathy in UK medical students: Differences by gender, medical year and specialty interest. Educ Prim Care 22:297-303.

Tay J, Siddiq T, Atiomo W. 2009. Future recruitment into obstetrics and gynaecology: Factors affecting early career choice. J Obstet Gynaecol 29(5):369-372.

Thapper M, Roussou E. 2013. Medical students' attitude towards rheumatology training at foundation years' level in the UK and rationale behind the students' choice: Results from a national survey. Rheumatol Int 33: 933-938.

Thistlethwaite J, Kidd MR, Leeder S, Shaw T, Corcoran K. 2008. Enhancing the choice of general practice as a career. Aust Fam Med 37(11):964-968.

Underwood MJ, Thompson M, McCaskie A. 1990. A Insight of first-year medical students into their future working conditions. Med Educ 24(3):210-211.

Van den Broek S, Muller B, Dekker N, Bootsma A, ten Cate O. 2010. Effect of the new Bologna bachelor degree on career considerations of medical students in one medical school. Med Teach 32(12):997-1001.

Van den Broek S, Ten Cate O, Wijnen-Meijer M, Van Dijk M. 2013. Effect of the Bologna bachelor degree on considerations of medical students to interrupt or terminate their medical training. Med Teach 36: 169-174.

van Tongeren-Alers T, van Esch M, Verdonk P, Johansson E, Hamberg K, Lagro-Janssen T. 2011. Are new medical students' specialty preferences gendered? Related motivational factors at a Dutch Medical School. Teach Learn Med Int J 23(3):263-268. 
Querido, S.J., Vergouw, D., Wigersma, L., Batenburg, R.S., Rond, M.E.J. de, Cate, O.T.J. ten. Dynamics of career choice among students in undergraduate medical courses. A BEME systematic review: BEME Guide No. 33. Medical Teacher: 2016, 38(1), 18-29

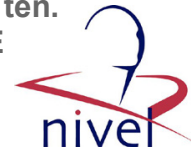

Vermeulen MI, Kuyvenhoven MM, Zuithoff NP, van der Graaf Y, Pieters HM. 2011. Uitval en stagnatie in de opleiding tot huisarts. Leeftijd, competenties en kennis spelen een rol Ned Tijdschr Geneeskd 155: A2780.

Vroom VH. 1964. Work and motivation. Oxford, England: Wiley. Wigney T, Parker G. 2008. Factors encouraging medical students to a career in psychiatry: Qualitative analysis. Aust N Z J Psychiatry 42:520-525.

Wijnen-Meijer M, Burdick W, Alofs L, Burgers C, Ten Cate OTJ. 2013. Stages and transitions in medical education around the world: Clarifying structures and terminology. Med Teach 35(4):301-307.

\section{TABLES AND FIGURES}

\section{Table 1. Search terms and strategy for health-related} databases.

\section{Medical students}

Students health occupations

or students public health

or medical students

or premedical students

or first year students

or final year students

or medical school student

or junior doctor

\section{and career preference/choice}

\section{Career choice \\ or career choices \\ or career preference \\ or career preferences}

Table 2. Inclusion and exclusion criteria applied to potentially relevant studies to determine the suitability for data synthesis.

\begin{tabular}{|c|c|c|}
\hline & Inclusion criteria & Exclusion criteria \\
\hline Population & $\begin{array}{l}\text { Medical students } \\
\text { One-tier undergraduate course according to routes } 1 \\
\text { and } 2^{*}\end{array}$ & $\begin{array}{l}\text { Health professional students other than medical } \\
\text { Medical courses with other routes* }\end{array}$ \\
\hline Outcome & $\begin{array}{l}\text { Study of factors associated with medical career prefer- } \\
\text { ences or choices }\end{array}$ & $\begin{array}{l}\text { Studies that did not investigate associations with career } \\
\text { preferences or choices (e.g., evaluation of educa- } \\
\text { tional programs, reasons for burn-out of medical } \\
\text { students) }\end{array}$ \\
\hline Study type & $\begin{array}{l}\text { Observational study design } \\
\text { Scientific articles }\end{array}$ & $\begin{array}{l}\text { Review } \\
\text { Editorials, comments, or opinion pieces }\end{array}$ \\
\hline
\end{tabular}


Querido, S.J., Vergouw, D., Wigersma, L., Batenburg, R.S., Rond, M.E.J. de, Cate, O.T.J. ten. Dynamics of career choice among students in undergraduate medical courses. A BEME systematic review: BEME Guide No. 33. Medical Teacher: 2016, 38(1), 18-29
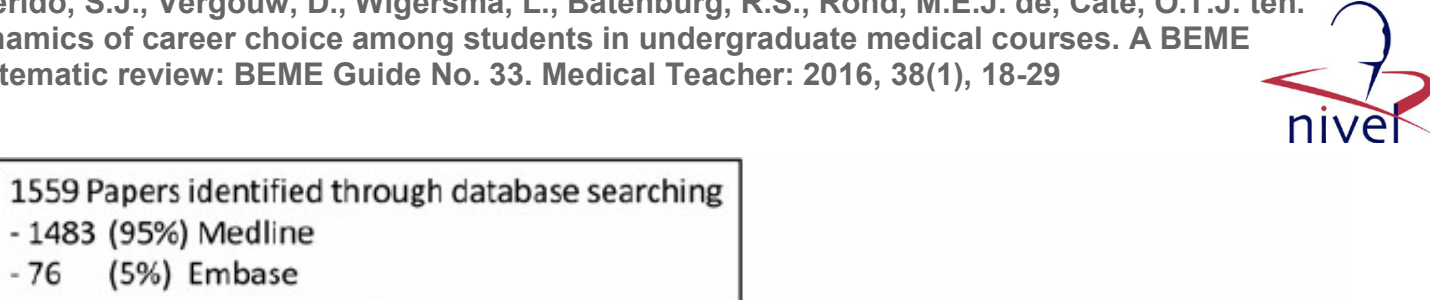

1274 Papers excluded after title \& abstract evaluation

285 Papers suitable for full-text evaluation

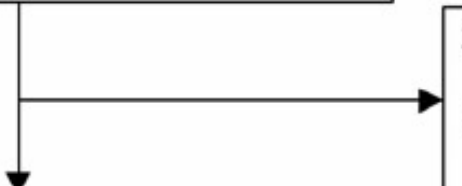

230 Papers excluded after full-text evaluation

1 Paper not available trough library, publisher or author

54 Papers suitable for analysis

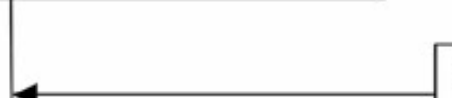

3 Additional papers identified by hand searching

57 Papers included in data synthesis

Figure 1. Flow diagram of literature search and paper selection. 
Querido, S.J., Vergouw, D., Wigersma, L., Batenburg, R.S., Rond, M.E.J. de, Cate, O.T.J. ten. Dynamics of career choice among students in undergraduate medical courses. A BEME systematic review: BEME Guide No. 33. Medical Teacher: 2016, 38(1), 18-29

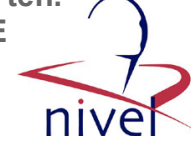

Table 3. Study characteristics and methodobgical quality of included studies.

\begin{tabular}{|c|c|c|c|c|}
\hline No & References & Design & $\begin{array}{c}\text { Pesp. } \\
\text { (\%5) }\end{array}$ & $\begin{array}{l}\text { Methods } \\
\text { quaity }\end{array}$ \\
\hline 1 & Cidand et a. (2012) & $\operatorname{CS}$ & 88 & 17 \\
\hline 2 & Takecha et al. (2013) & $\operatorname{cs}$ & $80 / 70$ & 17 \\
\hline 3 & Celand et a. (2014) & $\operatorname{cs}$ & acra1 & 16 \\
\hline 4 & Lefterve et a. (20103) & $\operatorname{cs}$ & 67 & 16 \\
\hline 5 & Lefente et a. $(2010 \mathrm{~b})$ & $\operatorname{cs}$ & 67 & 16 \\
\hline 6 & Lempp et a. (2012) & $\operatorname{cs}$ & 94 & 16 \\
\hline 7 & Binda et al. (2011) & $\operatorname{cs}$ & 97 & 15 \\
\hline 8 & Coubton et a. (2012) & $\operatorname{CS}$ & 100 & 15 \\
\hline 9 & Didertatsen et a. (2013) & $\operatorname{cs}$ & 87 & 15 \\
\hline 10 & Lampe et a. (2010) & $\operatorname{cs}$ & 90 & 15 \\
\hline 11 & Kulrigk et a. (2009) & $\operatorname{cs}$ & 87 & 15 \\
\hline 12 & Mahi et al. (2011) & $\operatorname{cs}$ & 99 & 15 \\
\hline 13 & Tarrbyraja et a. (2008) & $\operatorname{cs}$ & 87 & 15 \\
\hline 14 & Tay et a. $(2009)$ & $\operatorname{cs}$ & 89 & 15 \\
\hline 15 & van Tongeren-Akers et a. (2011) & $\operatorname{cs}$ & 94 & 15 \\
\hline 16 & Cotheng et a. $(2009)$ & LAC & 99 & 14 \\
\hline 17 & Dadis et a. $(2010)$ & LPP & 77 & 14 \\
\hline 18 & Dertsch et al. (2014) & LPC & 64 & 14 \\
\hline 19 & Gibis et a. (2012) & $\operatorname{cs}$ & 16 & 14 \\
\hline 20 & Heligers $(2012)$ & $\operatorname{cs}$ & 38 & 14 \\
\hline 21 & Heinz \& Jacob (2012) & $\operatorname{cs}$ & 16 & 14 \\
\hline 22 & Hughes et a. (2003) & $\operatorname{cs}$ & $99 / 28$ & 14 \\
\hline 23 & Kumar \& Dhalwa (2011) & $\operatorname{cs}$ & 79 & 14 \\
\hline 24 & Maiorone et al. (2008) & LPC & $\infty 9$ & 14 \\
\hline 25 & Mermood et al. $(2013)$ & $\operatorname{cs}$ & 92 & 14 \\
\hline 28 & Ravindina \& Ptageraid (2011) & $\operatorname{cs}$ & 65 & 14 \\
\hline 27 & Svrko et a. $(2013)$ & $\operatorname{cs}$ & 52 & 14 \\
\hline 28 & Soethout et a. (2008a) & $\operatorname{cs}$ & 77 & 14 \\
\hline 29 & Thapper \& Roussau (2013) & $\operatorname{cs}$ & - & 14 \\
\hline 30 & Dudid et a. (2011) & $\operatorname{cs}$ & - & 13 \\
\hline 31 & Deutsch et a. (2013) & LPP & 96 & 13 \\
\hline 20 & Rabadan \& Hikdago (2019) & LPP & $54 / 97$ & 13 \\
\hline 39 & Gedruse et a. (2012) & $\operatorname{cs}$ & 48 & 13 \\
\hline 34 & Hernann et a. (2012) & $\operatorname{cs}$ & 11 & 13 \\
\hline 35 & Kolbussa et a. (2011) & $\operatorname{cs}$ & 11 & 13 \\
\hline 36 & Maudisey et a. (2010) & LPC & - & 13 \\
\hline 37 & Robertson et a. (2009) & LPP & 11 & 13 \\
\hline 38 & Sternaser et a. (2013) & $\operatorname{cs}$ & 11 & 13 \\
\hline 39 & Abduighari et a. (2013) & $\operatorname{cs}$ & 67 & 12 \\
\hline$\Delta 0$ & N-Nuarni et al. $(2002)$ & $\operatorname{cs}$ & 20 & 12 \\
\hline 41 & Andlayer et a. (2012) & $\operatorname{cs}$ & 37 & 12 \\
\hline 42 & lerarim et al. (2014) & $\operatorname{cs}$ & 12 & 12 \\
\hline 43 & Subba et a. (2012) & $\operatorname{cs}$ & 75 & 12 \\
\hline 44 & Tarakd et a. (2011) & $\operatorname{cs}$ & 6 & 12 \\
\hline 45 & Pederan et a. (2011) & $\operatorname{cs}$ & 57 & 11 \\
\hline$\Delta 8$ & Wgnege Parker (2003) & $Q$ & 100 & 11 \\
\hline 47 & Baler et a. $(2013)$ & $\operatorname{cs}$ & 17 & 10 \\
\hline 48 & Chark et al. (2013) & LPC & 56 & 10 \\
\hline 49 & Ditrikwater et al. (2008) & $Q$ & 3 & 10 \\
\hline 50 & Ferrat et a. (2013) & $\operatorname{cs}$ & 47 & 10 \\
\hline 51 & Hadier et al (2013) & $\operatorname{cs}$ & - & 10 \\
\hline 52 & Roboins et a. (2011) & $\operatorname{cs}$ & 4 & 10 \\
\hline 53 & Fith \& Wass (2011) & LPC & $49 \sqrt{72}$ & 9 \\
\hline 54 & Thistetiwate et al. (2008) & $Q$ & 100 & 9 \\
\hline 56 & Mula et a. (2012) & $\operatorname{cs}$ & 29 & 8 \\
\hline 58 & Andlauer et a. (2013) & $\operatorname{cs}$ & - & 7 \\
\hline 57 & Praharaj et al. (2013) & $\operatorname{cs}$ & - & 5 \\
\hline
\end{tabular}

--urionowr; CS-cross-sectiona; LPC-longitudind, retrocpective cohort; LPC - bongituina, prospective cohort; LPP - bongiudina, pre-/post-design; Q- quilative. 
Querido, S.J., Vergouw, D., Wigersma, L., Batenburg, R.S., Rond, M.E.J. de, Cate, O.T.J. ten. Dynamics of career choice among students in undergraduate medical courses. A BEME systematic review: BEME Guide No. 33. Medical Teacher: 2016, 38(1), 18-29
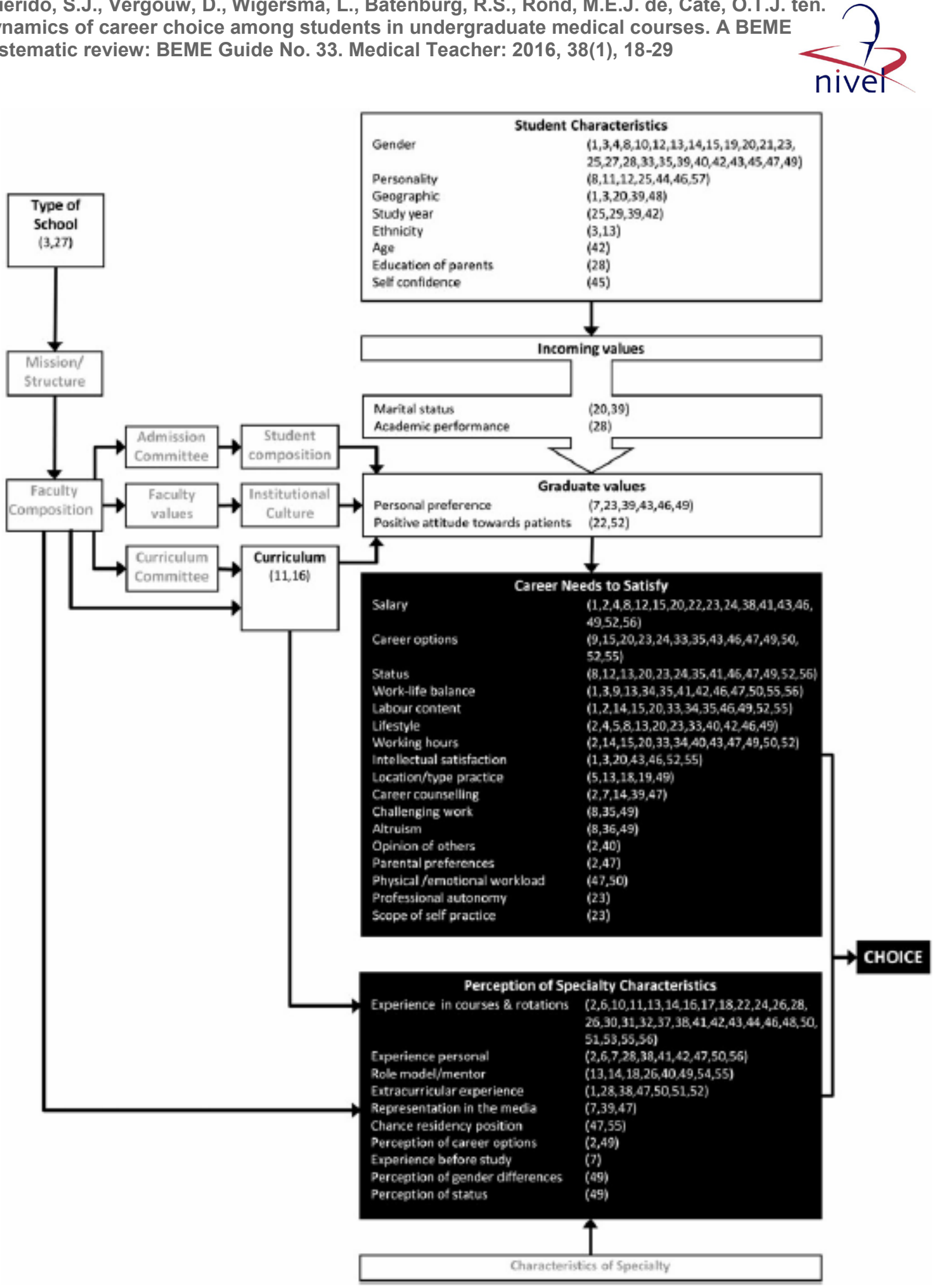

Figure 2. The factors identified by the data synthesis as assodated with medical spectalty preference or medical career choice ordered according to the Bland-Meurer model of medical career choice (Bland et al. 1995). Reference numbers rehate to the identification of studies from Table 3, in which studies are ordered according to their methodological quality (high quality: references $1-6$, moderate quality: references $7-38$, and low methodological quality: references 39-57). 
Querido, S.J., Vergouw, D., Wigersma, L., Batenburg, R.S., Rond, M.E.J. de, Cate, O.T.J. ten. Dynamics of career choice among students in undergraduate medical courses. A BEME systematic review: BEME Guide No. 33. Medical Teacher: 2016, 38(1), 18-29

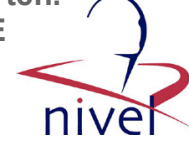

Table 4. Summary of findings; the number of studies with a high, moderate or low methoddogical quality in which a factor is associated with medical career decision-making.

\begin{tabular}{|c|c|c|c|}
\hline \multirow[b]{2}{*}{$\begin{array}{l}\text { Factors associated with medical } \\
\text { career choice/preference }\end{array}$} & \multicolumn{3}{|c|}{ Methodological quality } \\
\hline & High (17-16 points) & Moderate (15-13 points) & Low $(\leq 12$ points) \\
\hline \multicolumn{4}{|l|}{ Medical school characteristics } \\
\hline Type of school & 1 & 1 & - \\
\hline Curriculum & - & 2 & - \\
\hline \multicolumn{4}{|l|}{ Student characteristics } \\
\hline Gender & 3 & 15 & 7 \\
\hline Personality & - & 4 & 3 \\
\hline Geographic & 2 & 1 & 2 \\
\hline Study year & - & 2 & 2 \\
\hline Ethricity & 1 & 1 & - \\
\hline Age & - & - & 1 \\
\hline Education of parents & - & 1 & - \\
\hline Self confidence & - & - & 1 \\
\hline \multicolumn{4}{|l|}{ Student values } \\
\hline Personal preference & - & 2 & 4 \\
\hline Positive attitude towards patients & - & 1 & 1 \\
\hline Marital status & - & 1 & 1 \\
\hline Academic performance & - & 1 & - \\
\hline \multicolumn{4}{|l|}{ Personal needs } \\
\hline Salary & 3 & 8 & 6 \\
\hline Carøer options & - & 7 & 7 \\
\hline Status & - & 7 & 6 \\
\hline Work-life balance & 3 & 3 & 7 \\
\hline Labor content & 2 & 6 & 4 \\
\hline Lifestyle & 3 & 5 & 4 \\
\hline Working hours & 1 & 5 & 6 \\
\hline Intellectual satisfaction & 2 & 1 & 4 \\
\hline Location/type practice & 1 & 3 & 1 \\
\hline Career counseling & 1 & 2 & 2 \\
\hline Challenging work & - & 2 & 1 \\
\hline Altruism & - & 2 & 1 \\
\hline Opinion of others & 1 & - & 1 \\
\hline Parental preferences & 1 & - & 1 \\
\hline Physicalemotional workbad & - & - & 2 \\
\hline Professional autonomy & - & 1 & - \\
\hline Sccoe of self practice & - & 1 & - \\
\hline \multicolumn{4}{|l|}{ Perception of specialty characteristics } \\
\hline Experience in courses and rotations & 2 & 17 & 11 \\
\hline Experience personal & 2 & 3 & 5 \\
\hline Role modelmentor & - & 4 & 4 \\
\hline Extracurricular experience & 1 & 2 & 4 \\
\hline Representation in the media & - & 1 & 2 \\
\hline Chance residence position & - & - & 2 \\
\hline Perception of career options & 1 & - & 1 \\
\hline Experience before study & - & 1 & - \\
\hline Perception of gender differences & - & - & 1 \\
\hline Perception of status & - & - & 1 \\
\hline
\end{tabular}

